\title{
An examination of multiple factors affecting community structure in an aquatic amphibian community
}

\author{
Spencer A. Cortwright * and Craig E. Nelson \\ Department of Biology, Indiana University, Bloomington, IN 47405, USA
}

Accepted January 8, 1990

Summary. The potential effects of multiple factors structuring certain larval amphibian communities were studied using a pen experiment in a natural pond. Potential factors (predation and competition from other species) were allowed to act in a stepwise fashion such that their relative importance could be evaluated. Based on a previous study, it was hypothesized that predation by $\mathrm{Am}$ bystoma salamander larvae on other larval amphibian species would be the most important factor. Survival of Ambystoma jeffersonianum salamander larvae and Rana sylvatica tadpoles was significantly depressed only by Ambystoma opacum predation. Survival of Ambystoma maculatum salamander larvae was significantly greater in the absence of both $A$. opacum and $A$. jeffersonianum predators. The virtual elimination of Hyla chrysoscelis larvae in all treatments also can be largely attributed to Ambystoma predation. Thus, Ambystoma predation was the dominant factor determining larval survival of four amphibian prey species in the experimental communities.

Key words: Multiple factors - Predation - Competition - Community structure - Amphibians

Natural communities can be structured by multiple operating factors. For example, salamander predation can alter the competitive interactions among larval anuran prey (Morin 1983a). However, consideration of multiple factors in designing field experiments can be difficult (Quinn and Dunham 1983). Quinn and Dunham describe three types of problems in multiple factor experiments: (1) where multiple factors operate it is not possible to "distinguish between the "truth" of processes occurring simultaneously;" (2) univariate tests may not estimate the actual contributions of individual factors

* Present address and address for offprint requests: Department of Biology, University of Michigan, Ann Arbor, MI 48109, USA if there are strong interactions among factors; and (3) absence-of-effect null hypotheses may be difficult to construct.

A variety of direct and indirect interactions (predation, competition, competitive priority effects, and/or indirect facilitation) may influence the structure of aquatic larval amphibian communities (e.g. Seale 1980; Morin 1983a, b, 1986; Smith 1983; Wilbur 1984; Alford and Wilbur 1985; Wilbur and Alford 1985; Holomuzki 1986). Travis et al. (1985) emphasize the importance of considering multiple factors acting on larval amphibian populations. Previous results suggest that predation by Ambystoma opacum (marbled salamander) larvae results in low survivorship of Ambystoma jeffersonianum (Jeffer-

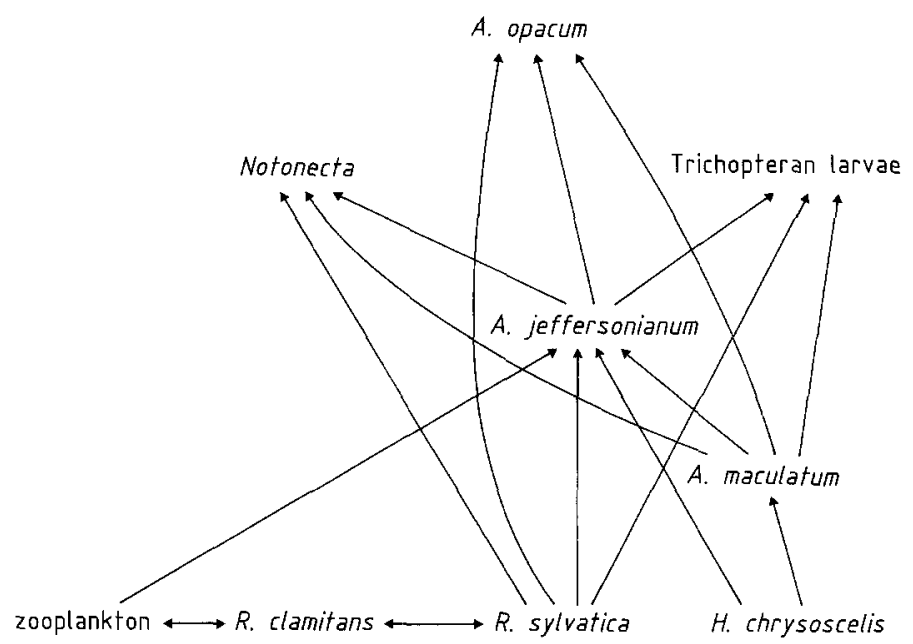

Fig. 1. Trophic interactions studied here. These interactions are those we hypothesized for ponds without abundant adult Notophthalmus viridescens (red-spotted newts). Newts probably occupy the same position as $A$. opacum. Some ponds lack certain species depicted here. Proposed interactions are based on known amphibian feeding habits, field observations, and Cortwright (1987). Double-pointed arrows indicate competitive interactions. Salamander larvae probably prey on immature Notonecta and Trichoptera, however, direct evidence has not been gathered 
son salamander) and Rana sylvatica (wood frog) larvae in both experimental and natural communities (Cortwright 1987). However, these species are embedded in a complex web of trophic interactions (Fig. 1). As a result, other predators and competitors acting over an entire season could also have affected the survivorship of the latter two species. Factors that could have reduced survival of $A$. jeffersonianum larvae included: (1) predation by larval $A$. opacum, (2) predation by aquatic invertebrates, (3) competition between Rana clamitans tadpoles (green frog) and the zooplankton prey of $A$. jeffersonianum larvae resulting in reduced availability of zooplankton to A. jeffersonianum, and (4) background physical and biological factors. Factors that could have reduced survivorship of $R$. sylvatica tadpoles included: (1) predation by larval $A$. opacum, (2) predation by larval A. jeffersonianum, (3) predation by aquatic invertebrates, (4) reduction of suspended particle resource levels by overwintering $R$. clamitans tadpoles to a point where $R$. sylvatica hatchlings starve (cf. Seale 1980) or die due to other causes related to low resource availability, and (5) background physical and biological factors.

The present study examines the impact of these multiple causes on $R$. sylvatica and $A$. jeffersonianum using stepwise addition of factors in a field experimental design. In addition, responses of the other amphibians to the various treatments were analyzed. Problems (1) and (2) outlined by Quinn and Dunham (1983) were largely obviated in that the design assessed the importance of factors added one at a time while still allowing several combinations of factors to act. Problem (3) is addressed by comparing each added factor to previous treatment(s) which do not include the factor in question. Not all combinations of factors were possible due to limitations on the number of available pens.

\section{Materials and methods}

The study site was a permanent pond $\left(330 \mathrm{~m}^{2}\right.$ when full) in Yellowwood State Forest, Brown County, Indiana. Details of pen construction and the study area are given elsewhere (Cortwright 1987, $1988)$. Each pen $(2.5 \times 1.0 \mathrm{~m})$ was built directly into the pond bottom thereby offering a natural, leaf and twig covered substrate. Vexar screen $(14 \times 6 \mathrm{~mm}$ mesh) was placed over the pens to control colonization by large insects and a hardware cloth shield ( $3 \mathrm{~mm}$ mesh) was sewn on the walls of each pen so metamorphs could not leave. The Vexar tops reduced sunlight by only ca. $12 \%$. Pen walls were fiberglass window screen $(7 \mathrm{meshes} / \mathrm{cm})$ supported by wood poles.

The stepwise experimental design (Table 1) focused on species interactions which may have resulted in the low survivorship of $R$. sylvatica, A. jeffersonianum, and, in some habitats, Ambystoma maculatum (spotted salamander) previously observed in natural

Table 1. Experimental design in the 1984 pen experiment. Each Ambystoma and Rana species was added at its hatching time in nature except for $A$. opacum and $R$. clamitans, which hatched the previous October and summer respectively. There were two replicates per treatment

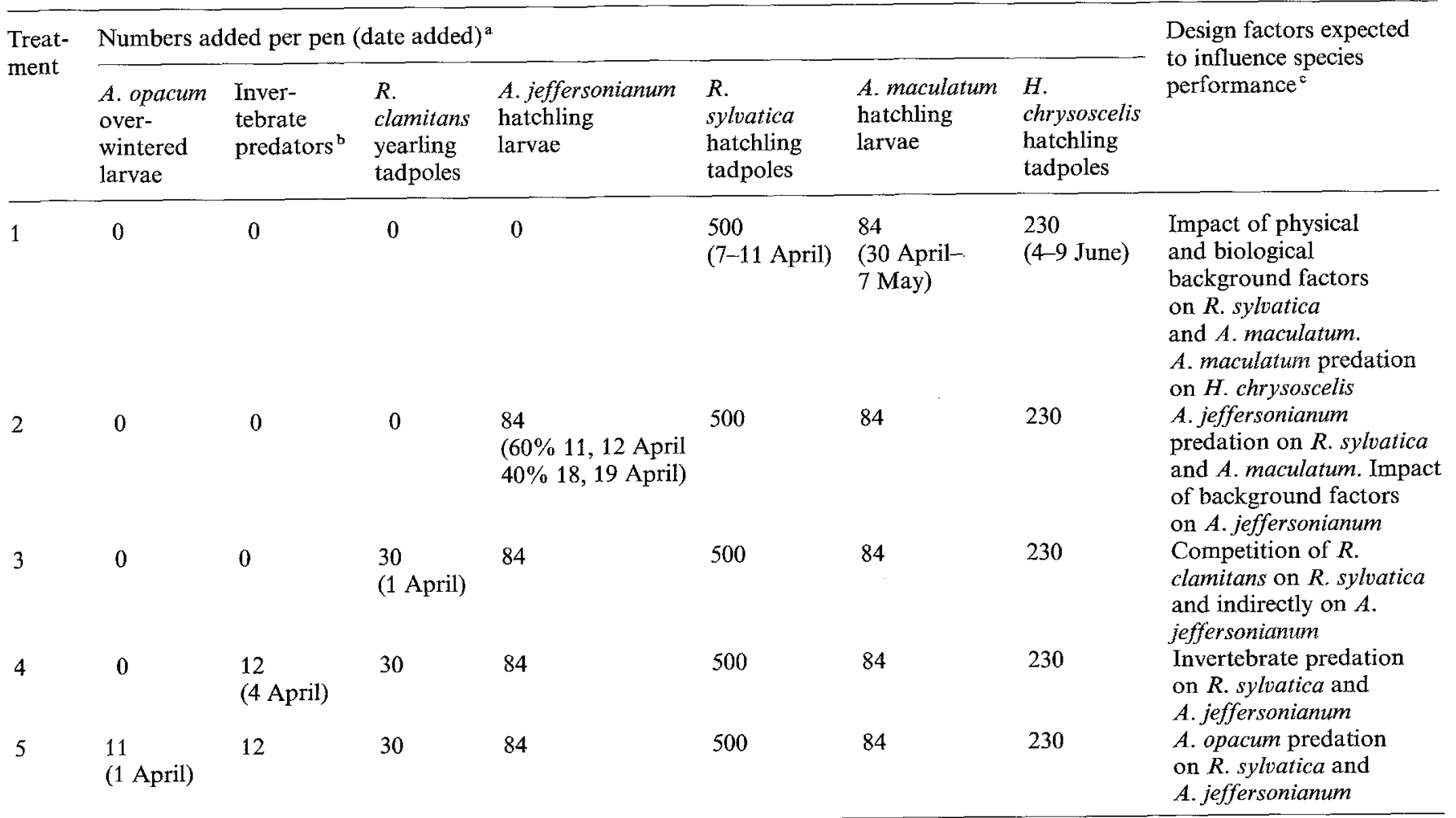

\footnotetext{
a $3 \mathrm{ml}$ strained volume of Chaoborus larvae (Diptera) were added to each pen on 7,15 April

b 7 Notonecta undulata adults (hemiptera), 5 Trichoptera larvae

- The factors operating on $H$. chrysoscelis and A. maculatum over treatments 2-5 parallel (except where noted) those on $R$. sylvatica and $A$.jeffersonianum respectively
} 
and experimental communities (Cortwright 1987). The design included amphibian larvae and two predaceous insects common in the study and nearby ponds in 1984. Specific predictions were: (1) R. sylvatica and $A$. jeffersonianum survivorship should be least in the presence of larval A. opacum predators, and (2) A. maculatum larvae should experience their highest survival in pens free of other species of salamander larvae (treatment 1). Both predictions were based on previous results (Cortwright 1987). However, the present design addressed the extent to which low survivorship through an entire growing season should be attributed to $A$. opacum predation, to other interactions (outlined above and see Table 1), or to background physical and biological factors. The design also allowed the examination of predatory impact by Ambystoma larvae on Hyla chrysoscelis (gray treefrog) tadpoles. All treatments and replicates (2) were randomly applied to 10 pens within a set of 22 (the other 12 pens were used for a separate study).

All amphibian larvae were introduced at their hatching time in nature, except $A$. opacum salamander larvae and $R$. clamitans tadpoles, which hatched the previous autumn and summer respectively. The latter two species were added prior to any other species in order to simulate the natural phenology. Also, H. chrysoscelis hatchlings were allowed to grow for a few days until they were too large to pass through the screen wall. Metamorphic amphibians were caught on floating boards, resting under boards on dry pen areas, or climbing on the pen walls at night. All densities used were within the range occurring in nearby natural communities (Cortwright 1987, 1988). Metamorphic individuals were collected daily (between $0100-0500 \mathrm{~h} \mathrm{2-3}$ times per week and after $0500 \mathrm{~h}$ other days), weighed in the lab (to the nearest $\mathrm{mg}$ ), and released the next day.

The three response variables measured for each species in each pen were: 1) number of survivors, 2) mean wet mass at metamorphosis, and 3) mean duration of larval period. Survivorship is most directly related to predation, except where solely competitive and background physical and biological factors operated. Smaller metamorphic body mass and longer larval period primarily reflect competitive and other density dependent processes, especially in permanent ponds where the threat of pond drying is absent. In some situations, slow growth may increase vulnerability to large predators over the larval period (Wilbur 1984). However, the predators used here are only effective on these amphibian prey during the early part of the prey's larval period (Cortwright 1987).

Species responses were analyzed using univariate oneway analysis of variance (ANOVA). Planned comparisons (Lindman 1974) were used to assess statistical significance of the two major predictions (above). When an ANOVA was statistically significant for metamorphic mass or larval period, Student-Newman-Keuls (SNK) a posteriori contrasts were used to assess which treatments differed. In general, examination of statistical significance across treatments allows one to infer which processes contributed to shifts in the response variable. In addition to oneway ANOVAs on mass at metamorphosis, intraspecific density effects were analyzed using linear regression of metamorphic mass on the number of metamorphs (as only one initial hatchling density was used per species).

\section{Results}

\section{Predation}

We predicted that Ambystoma opacum salamander larvae should produce a marked reduction (beyond all prior factors) in the survivorship of $R$. sylvatica and $A$. jeffersonianum. No $R$. sylvatica tadpoles survived in the presence of predatory $A$. opacum larvae (Table 2), although large numbers survived (15.0 to $58.4 \%$ ) in all other pens. The unequal variances among treatments for the number of surviving $R$. sylvatica were removed
Table 2. Summary of mean responses at metamorphosis for the one-way pen experiment with two replicates

\begin{tabular}{|c|c|c|c|c|c|}
\hline & \multicolumn{5}{|c|}{ Treatment } \\
\hline & 1 & 2 & 3 & 4 & 5 \\
\hline \multicolumn{6}{|c|}{ A. opacum salamander larvae } \\
\hline Initial density & 0 & 0 & 0 & 0 & 11 \\
\hline $\begin{array}{l}\text { Mean no. } \\
\text { survivors }\end{array}$ & - & - & - & - & 10.5 \\
\hline $\begin{array}{l}\text { Mean \% } \\
\text { survivorship }\end{array}$ & - & - & - & - & 95.5 \\
\hline Mean mass (mg) & - & - & - & - & 1286.6 \\
\hline $\begin{array}{l}\text { Mean larval } \\
\text { period (days) }\end{array}$ & - & - & - & - & 69.6 \\
\hline
\end{tabular}

$R$. clamitans yearling tadpoles

\begin{tabular}{lccccc} 
Initial density & 0 & 0 & 30 & \multicolumn{1}{l}{30} & \multicolumn{1}{l}{30} \\
Mean no. survivors & - & - & 24.5 & 27.5 & 29.0 \\
Mean \% & - & - & 81.7 & 91.7 & 96.7 \\
survivorship & & & & & \\
Mean mass (mg) & - & - & 2249.5 & 2029.2 & 2144.6 \\
Mean larval & - & - & 104.8 & 101.0 & 105.4
\end{tabular}

period (days) $^{\mathbf{a}}$

A. jeffersonianum salamander larvae

$\begin{array}{lccccc}\text { Initial density } & 0 & 84 & 84 & 84 & 84 \\ \text { Mean no. survivors } & - & 40.5 & 36.0 & 23.0 & 4.0 \\ \text { Mean \% } & - & 48.2 & 42.9 & 27.4 & 4.8 \\ \text { survivorship } & & & & & \\ \text { Mean mass (mg) } & - & 898.2 & 792.6 & 655.5 & 1099.0 \\ \text { Mean larval } & - & 119.6 & 125.0 & 127.2 & 101.0\end{array}$

period (days)

R. sylvatica tadpoles

\begin{tabular}{lrrrrr} 
Initial density & \multicolumn{1}{c}{500} & \multicolumn{1}{c}{500} & \multicolumn{1}{c}{500} & \multicolumn{1}{c}{500} & 500 \\
Mean no. survivors & 283.0 & 172.0 & 156.0 & 107.5 & 0 \\
$\begin{array}{l}\text { Mean \% } \\
\text { survivorship }\end{array}$ & 56.6 & 34.4 & 31.2 & 21.5 & 0 \\
$\begin{array}{l}\text { Mean mass (mg) } \\
\text { Mean larval }\end{array}$ & 234.8 & 287.7 & 298.8 & 273.6 & - \\
period (days) & 72.0 & 83.7 & 72.8 & 73.8 & - \\
& & & & &
\end{tabular}

A. maculatum larvae

$\begin{array}{lcrrcc}\text { Initial density } & 84 & 84 & 84 & 84 & 84 \\ \text { Mean no. survivors } & 67.5 & 0 & 2.5 & 4.0 & 7.0 \\ \begin{array}{l}\text { Mean \% } \\ \text { survivorship }\end{array} & 80.4 & 0 & 3.0 & 4.8 & 8.3 \\ \begin{array}{l}\text { Mean mass (mg) } \\ \text { Mean larval }\end{array} & 427.6 & - & 930.4 & 731.8 & 959.8 \\ \text { period (days) } & 103.2 & - & 129.0 & 119.6 & 102.8\end{array}$

H. chrysoscelis tadpoles

$\begin{array}{lrrrrr}\text { Initial density } & 230 & 230 & 230 & 230 & 230 \\ \text { Mean no. survivors } & 0 & 0 & 0 & 0 & 0.5 \\ \text { Mean \% } & 0 & 0 & 0 & 0 & 0.2 \\ \text { survivorship } & & & & & \end{array}$

a calculated from 1 April 
Table 3. One way ANOVAs on the number of surviving A. jeffersonianum, $R$. sylvatica, and $A$. maculatum and the duration of the larval period for $A$. jeffersonianum. Ln X and $\ln \mathrm{X}+1$ transformations were required for the number of surviving $A$. jeffersonianum and $R$. sylvatica, respectively

\begin{tabular}{|c|c|c|c|c|}
\hline Source of variation & $d f$ & $M S$ & $F$ & $P$ \\
\hline \multicolumn{5}{|c|}{ 1. A. jeffersonianum number surviving } \\
\hline Between treatments & 3 & 2.238 & \multirow[t]{2}{*}{10.833} & \multirow[t]{2}{*}{0.022} \\
\hline Error & 4 & 0.207 & & \\
\hline \multicolumn{5}{|c|}{ 2. R. sylvatica number surviving } \\
\hline Between treatments & 4 & 10.459 & \multirow[t]{2}{*}{36.316} & \multirow[t]{2}{*}{0.0007} \\
\hline Error & 5 & 0.288 & & \\
\hline \multicolumn{5}{|c|}{ 3. A. maculatum number surviving } \\
\hline Between treatments & 4 & 5.001 & \multirow[t]{2}{*}{9.195} & \multirow[t]{2}{*}{0.016} \\
\hline Error & 5 & 0.544 & & \\
\hline \multicolumn{5}{|c|}{ 4. A. jeffersonianum larval period } \\
\hline Between treatments & 3 & 284.46 & \multirow[t]{2}{*}{9.63} & \multirow[t]{2}{*}{0.027} \\
\hline Error & 4 & 29.54 & & \\
\hline
\end{tabular}

using a $\ln (\mathrm{x}+1)$ transformation (1 was added because $\ln 0$ is undefined when there are no survivors-treatment 5). The ANOVA was highly significant (Table 3) and the only significant treatment effect was from $A$. opacum predation (treatment 5 differs from each of $1-4$, a priori contrast $T=-11.9$, d.f. $=5, P<0.001$ ). Similarly, only 3.6 or $6.0 \%$ of $A$. jeffersonianum survived in the presence of $A$. opacum while many more $(20.2$ to $65.5 \%)$ survived in each of the other pens. A ln transformation of number surviving was required to meet the homogeneity of variance assumption. The ANOVA was significant (Table 3 ) and again, the only significant treatment effect was from $A$. opacum predation (treatment 5 differs from each of 2-4, a priori contrast $T=-5.6$, d.f. $=4, P=0.005$ ).

As predicted, the number of surviving $A$. maculatum salamander larvae decreased dramatically in the presence of $A$. jeffersonianum or $A$. opacum larvae as only 0 to $9.5 \%$ survived, while 60.7 or $100 \%$ survived in the treatment lacking these predators (Tables 2, 3). The reduction of $A$. maculatum survivorship when both predatory salamander larvae were present (treatment 5) was probably due largely to predation by $A$. opacum larvae as an average of only four $A$. jeffersonianum larvae survived per pen (Table 2). The predator-free treatment differed significantly from the others (treatment 1 differs from each of $2-5$, a priori contrast $T=5.3$, d.f. $=5, P=$ 0.003).

Only one $H$. chrysoscelis tadpole survived to metamorphosis. Survivorship in a small cage containing only $H$. chrysoscelis tadpoles showed that these tadpoles can survive well $(42 / 50)$ in this pond in the absence of other species. Most $A$. opacum larvae were at or near metamorphosis upon addition of $H$. chrysoscelis tadpoles and feeding activity decreases at this time (Walters 1975). One of us (SAC) has directly observed larval $A$. jeffersonianum feeding on $H$. chrysoscelis tadpoles in both natural settings and containers. Hence, the low survival of $H$. chrysoscelis was probably due to strong predatory pressure by larvae of $A$. maculatum (in all treatments) and/or $A$. jeffersonianum (in treatments 2-5).

In sum, all of the significant treatment effects were due to salamander predation (severe reductions down to $0-10 \%$ in survivorship). Thus, the prediction of strong predation by Ambystoma larvae was amply supported, especially for $A$. opacum. However, it should be noted that the estimated mean survival of $A$.jeffersonianum and $R$. sylvatica decreased as each potential species interaction was added across treatments. This suggests that some of the species interactions other than salamander predation may have had small, but not statistically detectable, effects on prey survival.

\section{Interspecific competition}

No $A$. jeffersonianum response variables were significantly different between treatments 2 and 3, those which tested competitive effects of $R$. clamitans on the prey of $A$. jeffersonianum (SNK $P>0.05$ ). Similarly, no $R$. sylvatica response variables were significantly different between treatments 2 and 3, those which tested direct competition of $R$. clamitans on $R$. sylvatica (SNK $P>$ 0.05 ).

If larvae of A. maculatum grow beyond a size vulnerable to $A$. jeffersonianum predation, then these two species might compete for resources, especially since ambystomatid larvae are typically generalist predators (Dodson and Dodson 1971; Wilbur 1972; Licht 1975; Walters 1975; Sever and Dineen 1977; Freda 1983; Collins and Holomuzki 1984; Taylor 1984). If $A$. jeffersonianum competition on $A$. maculatum was strong, then $A$. maculatum body mass should have increased markedly from treatments 3 and 4 to treatment 5, where few $A$. jeffersonianum survived. A. maculatum body mass increased (Table 2$)$, but not significantly so $\left(F_{2,3}=1.69, P>0.30\right)$. However, $A$. opacum, which may also compete with $A$. maculatum (see Stenhouse et al. 1983), was present in treatment 5 .

\section{Intraspecific competition}

Although increased density did not have a large direct impact on survivorship of the amphibian prey species tested (in the absence of salamander predators larval survival was generally high), density could affect larval growth. Specifically, the number of survivors to metamorphosis could produce density-dependence in mass at metamorphosis or length of larval period.

The relation between $A$. jeffersonianum metamorphic body mass and number surviving to metamorphosis was not statistically significant $\left(r^{2}=0.37, P=0.11\right)$. However, pen 15 (treatment 2) exhibited a strongly bimodal distribution of body masses (Fig. 2) with 11 individuals considerably larger than the rest. All other pens had a unimodal or bimodal distribution with only 1-3 large individuals. In some local ponds, large $A$. jeffersonianum larvae (>1.5 g) consumed $R$. sylvatica tadpoles nearly as wide as the salamander's jaws, and exhibited bimodal 


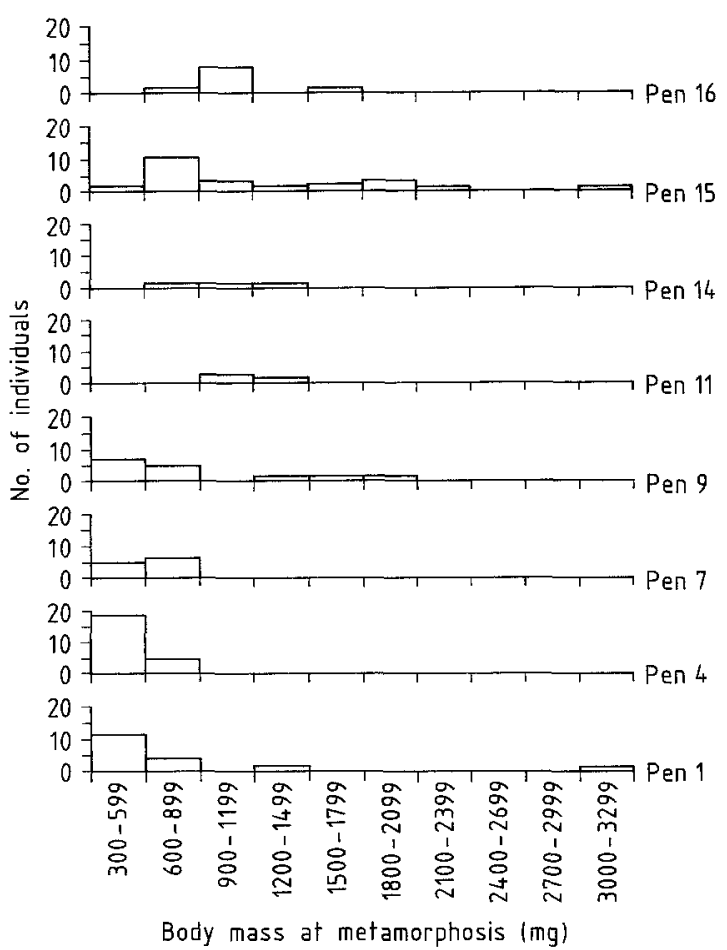

Fig. 2. Metamorphic A. jeffersonianum body mass distributions from each experimental pen

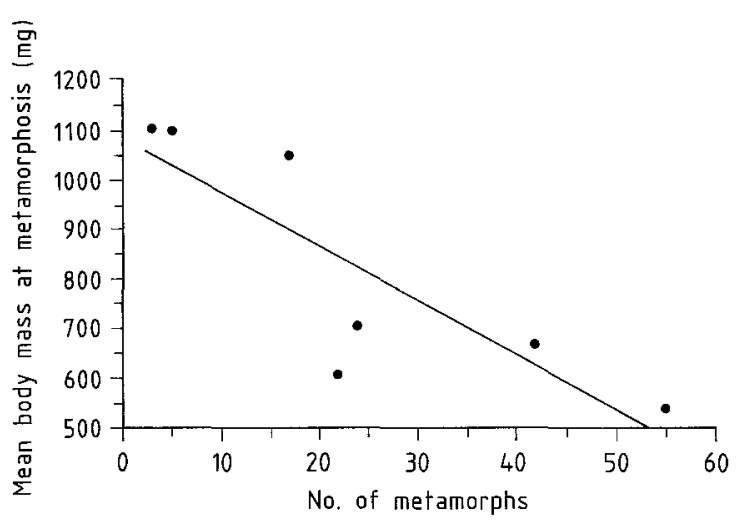

Fig. 3. Regression of metamorphic A. jeffersonianum body mass on number of $A$. jeffersonianum metamorphs. The regression equation is: Mean mass at metamorphosis $=-11.053$ (number of $A$. jeffersonianum metamorphs $)+1088.153 .\left(P=0.016, r^{2}=0.72\right)$

size distributions (Cortwright 1987). We suspect that in pen 15 a high number of $A$. jeffersonianum differed in resource utilization by preying on $R$. sylvatica tadpoles (this pen had only $76 R$. sylvatica metamorphose). If pen 15 is excluded from the analysis, there is a significant inverse relationship between metamorphic $A$. jeffersonianum body mass and the number surviving (Fig. 3). This suggests that intraspecific density had a strong effect on metamorphic body size.

The duration of larval period for $A$. jeffersonianum larvae differed statistically among treatments (Table 3 ). In most treatments, $A$. jeffersonianum larvae took 119 to 127 days to complete metamorphosis. However, in treatment 5, where by far the fewest survived, only 101 days were required (Treatment 5 versus each of 2-4,
SNK $P<0.05)$. This suggests an appreciable $(18-26 \%)$ increase in larval period as a result of intraspecific competition at higher densities. Overall, for $A$. jeffersonian$u m$ there was a significant difference among treatments in larval period (Table 3, treatments account for $88 \%$ of the variance) and also in number surviving (Table 3 , treatments account for $89 \%$ of the variance). Further, metamorphic mass was related to the number surviving (with pen 15 excluded-Fig. 3). Thus all three response variables were influenced by treatment conditions. However, the drastic reductions in survival should have the greatest influence on adult population size.

A linear regression of $A$. maculatum metamorphic mass on the number of metamorphs was not possible since the values of the independent variable were clumped (few survivors predominated). A oneway ANO$\mathrm{VA}$ of $A$. maculatum body mass (without treatment 2 with no survivors) showed that metamorphic mass varied among treatments $\left(F_{3,4}=13.81, P=0.014\right)$. In treatment 1 , where $A$. maculatum was the only Ambystoma and survived in high numbers, the metamorphic mass was significantly (SNK $P<0.05$ ) smaller than each of treatments $3-5$ by a factor of two (Table 2). This result suggests that intraspecific competition occurred. However, A. maculatum larval period did not vary significantly among treatments $\left(F_{2,3}=3.0, P=0.19\right)$ and formed no consistent pattern.

No other analyses of the response variables for $R$. sylvatica or $R$. clamitans (ANOVA) were statistically significant.

\section{Discussion \\ Naturalness of pens}

Before evaluating the major experimental results, it is important to assess the similarity of experimental and natural conditions. The pens used in this study were similar in size to pens or reconstructed habitats used in other studies (e.g. Wilbur 1972; Wilbur et al. 1983; Morin 1986). Doty's (1978) pens were larger, but the water level rapidly drew down in his pond. Larval salamander predators are basically sit and wait foragers (Smith and Petranka 1987; Cortwright pers obs). Thus, $2.5 \mathrm{~m}^{2}$ pens should not restrict their behavior during periods of foraging. Since the pens had natural pond bottoms, all foraging options were available to larvae except the shore line, which was available only when the water level dropped during summer. We have observed (night and day observations) both salamander and frog larvae utilizing all parts of pens (leaf litter, mud-water interface, open water, pen walls, patches of duckweed).

Growth of larvae in pens was generally similar to that in LJ pond (Table 4, compare with Table 2). Larval period and metamorphic mass for $A$. maculatum overlapped widely among pens and the pond (LJ has $A$. opacum and $A$. jeffersonianum predators so treatments 2-5 are most applicable). A. jeffersonianum larval period and metamorphic mass (only slightly) also overlapped (treatment 5 most applicable $-A$. opacum present in 
Table 4. Range of larval period and metamorphic mass for freeliving amphibian larvae in $\mathrm{LJ}$ pond (1984). A few extreme values for either variable were omitted (ranges are otherwise based on a complete capture of all individuals at a drift fence)

\begin{tabular}{lll}
\hline Species & $\begin{array}{l}\text { Larval period } \\
\text { (d) }\end{array}$ & $\begin{array}{l}\text { Metamorphic mass } \\
(\mathrm{mg})\end{array}$ \\
\hline A. opacum & $55-75^{\mathrm{a}}$ & $1470-2600$ \\
A. jeffersonianum & $71-194$ & $1090-2000$ \\
A. maculatum & $61-170$ & $430-1300$ \\
R. sylvatica & $64-81$ & $425-750$ \\
\hline
\end{tabular}

a from 1 April (same as stocking time in pens)

pond). Perhaps some crowding effects on $A$. jeffersonianum occurred in pens (however, we have sampled ponds with high densities of $A$. jeffersonianum that were targeted for metamorphosis in the range of $400-800 \mathrm{mg}$ ).

A. opacum in pens cannot be compared directly with $A$. opacum in the surrounding (LJ) pond. The initial A. opacum pen density was an estimate of what larval density would have been if raccoons had not destroyed $75 \%$ of $A$. opacum nests the previous autumn. (Many salamanders laid eggs under boards I had previously used around the pond. Raccoon(s) took advantage of this arrangement one night, thus producing atypically high mortality.) Consequently, we used about 3 times the density of $A$. opacum larvae observed in March (this assumed that in the absence of $75 \%$ mortality there would have been no major density dependent mortality over winter). As a result, $A$. opacum density was higher in the pens than the pond (Table 4 growth data reflect this). Data from another year, suggest at the very least that pens were not overly restrictive [1983-ME pit $\bar{x}=$ $1694 \mathrm{mg}$ metamorphic mass, range 1320-1960 (a low density pond); Op pit $\bar{x}=1254 \mathrm{mg}$, range $1150-1430$ LJ pond $\bar{x}=1227$, range $950-1575]$.

A direct comparison of $R$. sylvatica data from the pond with that from the pens is not reasonable either, since the remaining $A$. opacum in the pond consumed virtually all $R$. sylvatica $(0.15 \%$ survived to metamorphosis). R. sylvatica only survived in the pens that lacked $A$. opacum, which resulted in much higher densities. A nearby pond that lacked $A$. opacum and had dense $R$. sylvatica, had a range of larval period $(66-100 \mathrm{~d})$ and metamorphic mass $(170-400 \mathrm{mg})$ that overlapped widely with the means from the pens.

Taken together, these comparisons suggest that growth of larvae was fairly natural. Further, we have observed that initial growth in pens was similar to freeliving populations (it is during this time that vulnerability to predators is greatest). Individuals in pens with high density appeared to show reduced growth in the second half of their larval period; a time when they were less vulnerable to predators.

\section{Experimental results}

The stepwise comparison of several factors that may influence community structure of certain larval amphibi- an communities confirmed our prediction that predation by salamander larvae is a much stronger influence on prey survival than either predation by invertebrates or competition from other amphibians. In the absence of $A$. opacum, survival of $A$. jeffersonianum larvae ranged from $27.4-48.2 \%$. This exceeds survivorship both for A. jeffersonianum in nature (Cortwright 1987, unpub data, $\bar{x}=4.1 \%$, range $0.2-10.8 \%, n=15$ ) and for other aquatic amphibian larvae (Petranka and Sih 1986). However, in the presence of $A$. opacum, survivorship of $A$. jeffersonianum was markedly reduced to $4.8 \%$. This is well within the range commonly observed in nature both for $A$. jeffersonianum and other species (Cortwright 1987, unpublished data; Petranka and Sih 1986).

In the absence of $A$. opacum, survival of $R$. sylvatica was $21.5-56.6 \%$. The only natural $R$. sylvatica survival I found this high was $35.1 \%$ for the predator-free first season in a newly-enlarged roadway depression (previously too temporary). Survivorship can be in the range of $7.4-19.3 \%$ from ponds in which $A$. opacum have been killed overwinter. Survivorship of $0 \%$ (or very nearly so) is common in many ponds with either $A$. opacum or Notophthalmus viridescens (red-spotted newt) present (Cortwright 1987, unpub data). In the presence of salamander predators, A. maculatum survivorship dropped an order of magnitude from $80.4 \%$ to $0-8.3 \%$. Again, survivorship in the presence of predators is comparable to that in nature (Cortwright 1987, unpub data, $\bar{x}=$ $0.8 \%$, range $0-3.6 \%, n=20$ ). Based on observed and box sample tadpole density estimates, similar arguments can be made for $H$. chrysoscelis (it is difficult to get total egg input into ponds and as a result \% survivorship is unknown).

In sum, the presence of salamander predators in experimental pens at natural densities resulted in prey survival very similar to that found in nature. The other potential species interactions resulted in species survival much higher than natural. Thus, their relative impact on natural survivorship appears to be very small.

Even though the other factors tested were not statistically significant, there was a tendency for mean survival of both $A$. jeffersonianum and $R$. sylvatica to decrease as each potential interaction was added across treatments. Variance among replicates was high enough to preclude statistical significance. This suggests that some or all of these other species interactions may have small effects which might be statistically detectable with a design featuring more replicates. For example, field observations of $A$. jeffersonianum consuming $R$. sylvatica tadpoles show a definite predator-prey interaction. However, $A$. jeffersonianum is not capable of consuming whole $R$. sylvatica until both species are moderately large. Although A. jeffersonianum does prey on $R$. sylvatica in these communities, the rate was very low under the present experimental conditions.

Although only one density of each species was used here, a previous experiment that used various density combinations also indicated that predation was an important mechanism for structuring communities (Cortwright 1987). Larval $A$. opacum overwinter in the pond and their relatively large size in most ponds by the spring 
hatching of $A$. jeffersonianum and $R$. sylvatica often results in strong predation. $A$. opacum (if present) and $A$. jeffersonianum larvae drastically reduced larval $A$. maculatum survivorship. A. opacum larvae also prey heavily on $A$. maculatum larvae elsewhere (Doty 1978, Stenhouse 1985, Stenhouse et al. 1983). A. jeffersonianum hatch about 2-3 weeks before $A$. maculatum, usually grow quickly, and can prey on $A$. maculatum (Wacasey 1961 ; Walters 1975; Thompson and Gates 1982; Cortwright 1987). Also, A. jeffersonianum and A. maculatum larvae were large enough to virtually eliminate all $H$. chrysoscelis tadpoles.

Although $H$. chrysoscelis survivorship was extremely low, this does not mean this species cannot coexist with ambystomatid predators. $H$. chrysoscelis has an extended breeding period (maximum length May through early August) and survivorship could improve later in the breeding season in ponds where most Ambystoma have already metamorphosed. In addition, the presence of preferred alternate prey or increased habitat structure (Stenhouse 1985) could improve $H$. chrysoscelis survivorship.

Invertebrate predation did not have strong effects in these communities possibly because larval odonate predators were not abundant in the pond (nor in nearby ponds) in 1984 and were therefore not part of the experimental design. A naturally occurring average of 2.5 $(2.5 \mathrm{sd})$ Plathemis sp and 0.5 (0.8 sd) Aeschna constricta odonates metamorphosed from each pen. However, previous predator experiments showed $A$. constricta to have a relatively small influence on larval amphibian survivorship (Cortwright 1987). Plathemis naiads are smaller in size and presumably even less of a threat to larval amphibians. Strong invertebrate predators such as leeches, large odonates (e.g. Anax junius and Tramea lacerata), and large Dytiscus larvae (Coleoptera) (Brockelman 1969; Gill 1978; Caldwell et al. 1980; Formanowicz and Brodie 1982; Brodie and Formanowicz 1983; Smith 1983; Travis et al. 1985) were not present in the study pond (nor in others nearby).

Seale (1980) suggested that massive mortality of some anuran species due to competitive preemption of resources by Rana catesbeiana tadpoles occurred in a Missouri larval amphibian community. The addition of 30 large $R$. clamitans tadpoles per pen in treatment 3 addressed this phenomenon in the present study. No effects of $R$. clamitans on $A$. jeffersonianum and $R$. sylvatica (treatment 2 versus 3 ) were statistically detectable. At the density we used, massive mortality clearly did not occur from preemption of resources.

Intraspecific density effects, resulting in a densitydependent decrease in metamorphic body size, were evident for $A$. jeffersonianum larvae (Fig. 3 ), and for $A$. maculatum larvae in the absence of $A$. opacum and $A$. jeffersonianum. In other studies, a similar increase in intraspecific (and interspecific) competition occurs among larval anurans (Morin 1981, 1983a; Wilbur et al. 1983) and among salamanders (Wilbur 1972; Morin 1983b) in the absence of predators. However, if density-dependent effects on growth are most important early in the larval period, then reduced early larval growth may pro- long the period of susceptability to salamander predators. This could be an interaction of factors where single factor tests might fail (Quinn and Dunham 1983). A negative density effect may be most important for highly vulnerable prey that are typically susceptable to predation for a short time. Morin (1986) suggested no enhanced predation due to negative density effects among Pseudacris crucifer tadpoles (to newt predators), a prey species which has low vulnerability and a relatively long susceptable period.

\section{Examples of multiple factors operating in other systems}

Predation and competition often interact in natural communities as (reviewed in Sih et al. 1985). For aquatic larval amphibian communities, Wilbur (1984) proposed a model and presented evidence that salamander predation acts first on hatchling tadpole species, and that subsequent competition occurs only if enough prey survive. Increased densities of salamander predators lessen the competitive interactions among tadpole species (Morin 1981, 1983a). Further, predation sometimes may be strong enough to eliminate or reduce tadpole populations to a point where competition is unimportant (Wilbur et al. 1983). Adult newts (Notophthalmus viridescens dorsalis) and larval tiger salamanders (Ambystoma tigrin$u m$ ) interact in a complex way. Predation by newts depresses larval tiger salamander survival and mean metamorphic mass while predation by surviving tiger salamander larvae on newt larvae released adult and larval newts from intraspecific competition (Morin 1983b).

Other biotic factors sometimes interact with predation in structuring natural communities. Two examples are (1) immigration abilities by small mammals on to islands can determine which mammal species are present (predators restricted to closer islands - Lomolino 1984) and (2) habitat selection and resource use in desert rodents can influence which species are most vulnerable to predation (Kotler 1984).

Abiotic factors sometimes affect the extent to which predation structures communities. For example, in stream insect communities, Peckarsky (1985) found that siltation can override the effect of predation on community structure. Flood disturbance can alter predatorprey interactions between mosquitofish and topminnows (Meffe 1984) and between fish and larval Ambystoma texanum (Petranka and Sih 1986). Winter oxygen stress can eliminate dominant predators, and possibly competitors as well, in lake fish assemblages (Tonn 1985, Tonn and Magnuson 1982).

Abiotic factors have also been studied in relation to competition. Disturbance and habitat duration influenced the structure of a benthic stream community (McAuliffe 1984). One species of caddisfly competitively dominated the community on stable rocks. More equitable species distributions occurred on more disturbed (overturned) rocks. In temporary stream areas, a second species with a shorter generation time dominated the community. Schoener's (1983) review of competition provides several other examples (the most common abiotic factor was variable intensity of drought). 


\section{Multiple factors operating in this study}

The above studies emphasize that communities are often structured by several interacting factors. Yet, the experiment presented here suggests that one factor, predation by salamander larvae, largely determined structure (relative abundance) in certain larval amphibian communities. Intraspecific competition is enhanced when predators are absent. However, the large reduction in numbers surviving when predators are present is probably more important to population size than is the shift in body size of the few that escape predation. Further, in the absence of predators, no treatments significantly affected growth (metamorphic mass or larval period). This suggests that other factors probably did not enhance predation by depressing prey growth.

However, environmental factors inherent in the experimental design do play a role in determining community structure. For example, winter harshness determines overwintering survival of predatory species. In two nearby small ponds the 1983-84 and 1984-85 overwintering populations of $A$. opacum larvae were eliminated, probably by prolonged ice cover resulting in anoxia (strong hydrogen sulfide odor under the ice-Cortwright pers obs). In subsequent summers, $A$. jeffersonianum and $R$. sylvatica larvae dominated. A. maculatum larvae were eliminated (no metamorphs were caught using standard drift fence techniques, e.g. Stenhouse 1985), probably by $A$. jeffersonianum predation. This situation is similar to treatments $2-4$. A. opacum larvae were again killed during the winter of 1985-6. In addition, in one of the two ponds, most $A$. jeffersonianum embryos were killed by a March 1986 freeze. For the first time since at least $1983, A$. maculatum successfully produced metamorphs from this pond (Cortwright unpublished data). This second situation is similar to treatment 1 . In a mild winter (1982-83), A. opacum salamander larvae were the dominant species, and acted as strong predators on $A$. jeffersonianum, $A$. maculatum, and $R$. sylvatica (Cortwright 1987). This third situation is similar to treatment 5 . Thus, in these ponds winter harshness strongly affects which alternative community structure is realized.

A second environmental factor was inherent in the experimental design. Since the experiment used a permanent pond, species such as $R$. clamitans, which requires a year long tadpole period, and $A$. maculatum, which metamorphoses in late summer or early fall, were members of the community. In other nearby ponds, the species composition may be largely determined by the shorter pond duration (Cortwright 1987, c.f. Semlitsch 1983).

Thus, our abilty to detect which factors are important in structuring a community depends in part on the level at which we study the community. The study presented here compared species interactions operating simultaneously and found vertebrate predation to predominate. Another important factor, winter harshness, operated outside the temporal scope of the experiment but was reflected in the treatments selected (e.g. the presence or absence of A. jeffersonianum and/or A. opacum). Another important factor affecting the natural commu- nities modeled is habitat duration, which was held constant across all treatments and was not a factor in this experimental design. Thus, multiple factors do operate in structuring the communities examined here. One of these is the strong species interaction which the experiment documented.

Acknowledgements. We thank G. Cheplick, K. Clay, J. Holomuzki, D. Parkhurst, J. Petranka, and two reviewers for many helpful comments on earlier versions of the manuscript. We thank Don Duncan and Lee Eckhart for permission to use Yellowwood State Forest. The research was supported by an Indiana Academy of Science grant, a Sigma Xi Grant-in-aid of Research, and an Indiana University grant-in-aid. Repeated support from Indiana Academy of Science was especially helpful.

\section{References}

Alford RA, Wilbur HM (1985) Priority effects in experimental pond communities: competition between Bufo and Rana. Ecology 66:1097-1105

Brockelman WY (1969) An analysis of density effects and predation in Bufo americanus tadpoles. Ecology 50:632-644

Brodie ED Jr, Formanowicz DR Jr (1983) Prey size preference of predators: differential vulnerability of larval anurans. Herpetologica 39:67-75

Caldwell JP, Thorp JH, Jervey JO (1980) Predator-prey relationships among larval dragonflies, salamanders, and frogs. Oecologia 46:285-289

Collins JP, Holomuzki JR (1984) Intraspecific variation in diet within and between trophic morphs in larval tiger salamanders (Ambystoma tigrinum nebulosum). Can J Zool 62:168-174

Cortwright SA (1987) Impacts of species interactions and geographical-historical factors on larval amphibian community structure. PhD thesis. Indiana University, Bloomington, p 226

Cortwright SA (1988) Intraguild predation and competition: an analysis of net growth shifts in larval amphibian prey. Can J Zool 66:1813-1821

Dodson SI, Dodson VE (1971) The diet of Ambystoma tigrinum larvae from western Colorado. Copeia 1971:614-624

Doty TL (1978) A study of larval amphibian population dynamics in a Rhode Island vernal pond. $\mathrm{PhD}$ thesis. University of Rhode Island, Kingston, $\mathrm{p} 132$

Formanowicz Dr Jr, Brodic ED Jr (1982) Relative palatabilities of members of a larval amphibian community. Copeia 1982:9197

Freda J (1983) Diet of larval Ambystoma maculatum in New Jersey. J Herpetol 17:177-179

Gill DE (1978) The metapopulation ecology of the red-spotted newt, Notophthalmus viridescens (Rafinesque). Ecol Monogr 48:145-166

Holomuzki JR (1986) Predator avoidance and diel patterns of microhabitat use by larval tiger salamanders. Ecology 67:737-748

Kotler BP (1984) Risk of predation and the structure of desert rodent communities. Ecology 65:689-701

Licht LE (1975) Growth and food of larval Ambystoma gracile from a lowland population in southwestern British Columbia. Can J Zool 53:1716-1722

Lindman HR (1974) Analysis of variance in complex experimental designs. W.H. Freeman and Co, San Francisco, California, USA

Lomolino MV (1984) Immigrant selection, predation, and the distributions of Microtus pennsylvanicus and Blarina brevicauda on islands. Am Nat 123:468-483

McAuliffe JR (1984) Competition for space, disturbance, and the structure of a benthic stream community. Ecology 65:894-908 
Meffe GK (1984) Effects of abiotic disturbance on coexistence of predator-prey fish species. Ecology 65:1525-1534

Morin PJ (1981) Predatory salamanders reverse the outcome of competition among three species of anurans. Science 212:1284 1286

Morin PJ (1983a) Predation, competition, and the composition of larval anuran guilds. Ecol Monogr 53:119-138

Morin PJ (1983b) Competitive and predatory interactions in natural and experimental populations of Notophthalmus viridescens dorsalis and Ambystoma tigrinum. Copeia 1983:628-639

Morin PJ (1986) Interactions between intraspecific competition and predation in an amphibian predator-prey system. Ecology $67: 713-720$

Peckarsky BL (1985) Do predaceous stoneflies and siltation affect the structure of stream insect communities colonizing enclosures? Can J Zool 64:1519-1530

Petranka JW, Sih A (1986) Environmental instability, competition, and density-dependent growth and survivorship of a streamdwelling salamander. Ecology 67:729-736

Quinn JF, Dunham AE (1983) On hypothesis testing in ecology and evolution. Am Nat 122:602-617

Schoener TW (1983) Field experiments on interspecific competition. Am Nat 122:240-285

Seale DB (1980) Influence of amphibian larvae on primary production, nutrient flux, and competition in a pond ecosystem. Ecology $61: 1531-1550$

Semlitsch RD (1983) Structure and dynamics of two breeding populations of the eastern tiger salamander Ambystoma tigrinum. Copeia 1983:608-616

Sever DM, Dineen CF (1977) Reproductive ecology of the tiger salamander, Ambystoma tigrinum, in northern Indiana. Proc Indiana Acad Sci 87:189-203

Sih A, Crowley P, McPeek M, Petranka J, Strohmeier K (1985) Predation, competition, and prey communities: a review of field experiments. Ann Rev Ecol Syst 16:269-311

Smith CK, Petranka JW (1987) Prey size-distributions and sizespecific foraging success of Ambystoma larvae. Oecologia $71: 239-244$

Smith DC (1983) Factors controlling tadpole populations of the chorus frog (Pseudacris triseriata) on Isle Royale, Michigan. Ecology 64:501-510

Stenhouse SL (1985) Interdemic variation in predation on salamander larvae. Ecology 66:1706-1717

Stenhouse SL, Hairston NG, Cobey AE (1983) Predation and competition in Ambystoma larvae: field and laboratory experiments. J Herpetol 17:210-221

Taylor J (1984) Comparative evidence for competition between the salamanders Ambystoma gracile and Taricha granulosa. Copeia 1984:672-683

Thompson EL, Gates JE (1982) Breeding pool segregation by the mole salamanders, Ambystoma jeffersonianum and Ambystoma maculatum, in a region of sympatry. Oikos $38: 273-279$

Tonn WM (1985) Density compensation in Umbra-Perca fish assemblages of northern Wisconsin lakes. Ecology 66:415-429

Tonn WM, Magnuson JJ (1982) Patterns in the species composition and richness of fish assemblages in northern Wisconsin lakes. Ecology 63:1149-1166

Travis J, Keen WH, Juiliana J (1985) The effects of miltiple factors on viability selection in Hyla gratiosa tadpoles. Evolution 39:1087-1099

Wacasey JW (1961) An ecological study of two sympatric species of salamanders, Ambystoma maculatum and Ambystoma jeffersonianum, in southern Michigan. $\mathrm{PhD}$ thesis. Michigan State University, East Lansing, p 117

Walters B (1975) Studies of interspecific predation within an amphibian community. J Herpetol 9:267-279

Wilbur HM (1972) Competition, predation, and the structure of the Ambystoma-Rana sylvatica community. Ecology 53:3-21

Wilbur HM (1984) Complex life cycles and community organization in amphibians. In: Price PW, Slobodchikoff CN, Gaud WS (eds). A New Ecology. John Wiley and Sons, New York, pp 195-224

Wilbur HM, Alford RA (1985) Priority effects in experimental pond communities: responses of Hyla to Bufo and Rana. Ecology 66:1106-1114

Wilbur HM, Morin PJ, Harris RN (1983) Salamander predation and the structure of experimental communities: anuran responses. Ecology 64:1423-1429 